\title{
Events, Processes, and the Time of a Killing
}

[Penultimate draft; final version forthcoming in Ratio]

Abstract The paper proposes a novel solution to the problem of the time of a killing (ToK), which persistently besets theories of act-individuation. The solution proposed claims to expose a crucial wrongheaded assumption in the debate, according to which ToK is essentially a problem of locating some event that corresponds to the killing. The alternative proposal put forward here turns on recognizing a separate category of dynamic occurents, viz. processes. The paper does not aim to mount a comprehensive defense of process ontology, relying instead on extant defenses. The primary aim is rather to put process ontology to work in diagnosing the current state of play over ToK, and indeed in solving it.

\section{The time and place of a killing}

It is no wonder that the problem of the time of a killing has attracted as much attention as it has in the fifty odd years since its initial formulation. Besides the persistent elusiveness of a fully satisfactory solution, interest in the puzzle is due in no small part to its cutting to the core of foundational issues in the metaphysics of mind and action. In particular, the puzzle vexes the question of act individuation, with different proposed solutions corresponding to different positions on how actions should be individuated.

The problem of the time of a killing (henceforth, ToK) is illustrated in a scenario where the queen pours poison into the king's ear at a certain time $\left(\mathrm{t}_{0}\right)$ and place $\left(\mathrm{p}_{0}\right)$. The king is then rushed to hospital $\left(\mathrm{p}_{1}\right)$ where he finally dies from his condition three days later $\left(\mathrm{t}_{3}\right)$. It seems undeniable that the queen killed the king, and moreover that she did so by pouring poison into his ear. But now we ask: When and where did the queen kill the king? One prominent answer zeroes in on the time and place at which the queen did what she did to kill the king, namely $t_{0} / \mathrm{p}_{0}$. If the queen killed the king by pouring poison into his ear, then that seems to give the time and place at which she performed the action of killing him. Call this the Davidsonian position. It flows from an entrenched view of act-individuation associated with Donald Davidson (1980, Essay 1. See also Anscombe, 1957), on which actions are thought to be identical to bodily movements. And if the queen's killing the king is indeed her pouring poison into his ear, then it seems like the former 
should be spatio-temporally collocated with the latter. The problem, however, is that the king died at a different location from where he was poisoned, namely $\mathrm{t}_{3} / \mathrm{p}_{1}$. Hence, the Davidsonian response seems committed to the highly counterintuitive claim that the queen killed the king before the king died. If the Davidsonian response cannot get around this difficulty, that would seem to impugn not just its proposed solution to ToK but the underlying theory of actindividuation as well. ${ }^{1}$

The main extant alternative to the Davidsonian response is one that will be dubbed here 'Thomsonian' after its classic exposition by Judith Jarvis Thomson (1971). This response takes an extended view of the killing's location so that it includes the entire interval from $t_{0} t_{0} t_{3}$. In this way, the Thomsonian avoids having to say that the king was killed before he died. But it seems to have a different and no more palatable implication, referred to sometimes as 'the problem of the acting dead'. Suppose the queen herself dies at $t_{1}$, just after she administers the poison. Since the Thomsonian proposes that the queen killed the king throughout $t_{0}-t_{3}$, it seems forced to accept that she killed him after she herself died; that is, that she acted while being dead (see Bennett, 1988: 196, and Bach, 1980: 119. For a response, see Ruben, 1999).

Much like the two main positions on ToK just canvassed, the present paper also traces the source of the problem to a foundational ontological controversy - but crucially, this is a controversy that has been almost entirely overlooked in discussions of ToK. The controversy in question is whether our ontology can make do with characterizing dynamic occurents exclusively as events or whether, alternatively, we must also recognize a separate category of processes. The paper argues that the latter - a minority view that has nonetheless been gaining ground in recent years holds the key to a compelling novel solution to ToK. The aim in what follows is therefore not to mount a comprehensive defense of process ontology; such defenses can be found elsewhere (Mourelatos, 1978; Galton and Mizoguchi, 2009; Hornsby, 2012; Steward, 2013; Stout, 2018). The

\footnotetext{
1 The problem is not restricted to acts of killing in particular, and other act-types are mentioned below. For convenience, the spatial location of the action will henceforth be ignored, focusing only on its temporal location.
} 
aim is rather to articulate an attractive solution that processes provide to a persistent problem, and to thereby demonstrate one important and neglected contribution they can make to philosophy of action. But if that aim is achieved, then of course the case for recognizing processes will have been indirectly bolstered as well, by drawing out one of its fruitful applications.

The quick and dirty exposition above sets out the bare bones of the two predominant positions on ToK and the central problem each faces, respectively. A recent discussion cites 'two views that have dominated the literature. First, the killing may be thought to be identical with the event that the agent performs. Alternatively, we may think that the killing is identical to the complex event composed of both the action of the agent and the death of the victim' (Silver, 2018: 1391; emphases added). There is much that can be, and indeed has been, disputed even in such a short passage as this. But in what follows the focus will instead be on a key implicit assumption that is shared by virtually all participants in the debate, and has been made salient in the passage above by italicizing the relevant terms - namely, the assumption that solving ToK is a matter of identifying the event which corresponds to the queen's killing of the king. Rejecting that assumption brings into view novel resources that make for a compelling solution to ToK, as argued below. But first, we must gain a basic understanding of what a view that urges the introduction of processes might look like.

\section{Events vs. processes in philosophy of action}

The predominant way of characterizing dynamic occurrents in philosophy of action (and beyond) owes much to a series of hugely influential papers by Donald Davidson (1980, especially Essays $1,3,4,5, \& 6)$, where he argued inter alia that ordinary thought and talk is committed to quantifying over events which are equivalent to our actions. When illustrating his analysis of the logical form of action sentences, Davidson famously worked with this example: 'Jones buttered the toast, slowly, deliberately, in the bathroom, with a knife, at midnight' (1980: 106). Abstracting 
away from the particular details of Davidson's final analysis, the important point for present purposes is that it is built around the idea that the thing the sentence refers to as what Jones did his action - is an event.

Now, the minority opposition to this view (a minority which seems to be steadily growing in recent years; see some references above) tends to highlight the fact that the sentences whose form Davidson was concerned to reveal are characterized by perfective aspect. And this, it is said, conceals crucial temporal features of actions which are temporally structured entities, compressing the action into one single moment. As Bernard Comrie puts it in his seminal treatment of aspect (Comrie, 1976), the perfective formulation 'presents the totality of the situation referred to ... without reference to its internal temporal constituency: the whole of the situation is presented as a single unanalyzable whole, with beginning, middle, and end rolled into one' (1976: 3). Such formulations need not amount to outright denying the temporal structure of actions so much as to abstracting away from any such structure, thereby consigning it to play no role in our theorizing. The corresponding ontology is inevitably impoverished, shorn of the resources to adequately represent the temporality of actions. The antidote comes from focusing on action sentences with imperfective aspect. If we consider instead 'Jones was buttering a piece of toast...', we take a perspective on the deed not as having been done, but rather as ongoing, which reveals the different patterns according to which actions come to occupy time - persisting, unfolding, enduring, and so on. $^{2}$

To see this more concretely, consider various features we ordinarily attribute to actions in connection with their temporal profile. Take, for example, the capacity to change mid-course. (I am not referring to the familiar claim that every action constitutes a change, but rather to actions

\footnotetext{
2 Settling certain in-house disputes is important when it comes to the precise formulation of the process view. Primarily perhaps, there is the question of whether processes are mass- or count-quantified. On the former view, defended for example by Hornsby (2012), the domain of agency comprises stuff-like activities (the process of running, reading, pushing a cart, etc.) of which individual, count-quantified events are composed. In contrast, the latter view, favoured by Steward (2013), endorses also individual processes. The distinction is glossed over in the text, however, since it does not affect the main line of argument.
} 
themselves undergoing change.) One's eating can become more hurried, one's driving less attentive, one's buttering more theatrical. The claim is that only the process view, with its sensitivity to the temporal constituency of actions, can accommodate this feature of actions. For to undergo change implies the existence of a persisting entity that loses some property (or more) it originally had and gains another of the same domain. This is not possible for events, since 'an event simply consists of the temporal parts of which it consists and ... variation in some quality amongst those parts does not constitute a change in the event itself, any more than a pole's being red on top and blue on the bottom constitutes a change in the pole' (Steward, 2012: 384). At most we can say that 'certain temporal parts of the event have properties different from those possessed by other temporal parts of that same event' (Steward, 2012: 378) - just like part of the pole is blue and another is red without this implying any change in the pole.

The only other sense we can try to make of change in events is to think of the whole event as changing. But an event that is some completed change or other cannot itself change, on pain of becoming a different change and hence a different event. This is often put by saying that events conform to the doctrine of Mereological Essentialism, meaning that they have their temporal parts essentially (for defenses see, among others, Lombard 1986, Simons 1987, and Neale 1993). ${ }^{3}$ It is only if $X$ is (or was) progressing that we can speak of $X$ as having changed at some point while still remaining one and the same $X$. For the ability to survive change presupposes the sort of persistence that only processes exhibit: the progressing occurrent persists through its temporal course and in so doing, it can also persist through change.

Consider next some action's being intermittent (Steward, 2013: 801-2). Take one's flashing a light from $t_{1}-t_{7}$, for example. To see one's flashing here as intermittent is to see it as progressing in accordance with a particular, stop-start, pattern. That pattern may well be constituted by

\footnotetext{
${ }^{3}$ Notice also that Mereological Essentialism implies the modal claim that no event could have lasted for a longer or shorter period than it actually did. But actions in fact seem to be modally more robust than that: one's practicing the violin could have lasted a while longer than it did, while remaining the same practicing. This is another intuitive feature of actions that only a process ontology seems able to deliver.
} 
individual flashing events. But it is not to any one of those events that we ascribe intermittence. Nor is it to the whole event spanning $\mathrm{t}_{1}-\mathrm{t}_{7}$. For 'intermittent' describes what happens when one stage (or sub-event) of the light's coming on is followed by another stage (or sub-event) of its coming off, and so on. In other words, it describes something as occurring, then ceasing, then reoccurring, then ceasing... But when we are thinking of this sequence as a completed whole, we are thinking of it not in terms of this pattern of progression but rather as an interconnected series of events having occurred at certain intervals. And that series, viewed as one completed whole, was never intermittent: it never occurred, ceased, reoccurred, and so on; it simply occurred once and was over. Many other temporal properties of actions - e.g. their being continuous, constant, sporadic, irregular, steady, etc. (Steward 2013, Ibid) - also require, for structurally similar reasons, a processual perspective if their attribution is to make sense.

A further, related feature of actions-qua-processes is likewise important for the solution to ToK proposed below. This is the so-called 'imperfective paradox'. It concerns how an action may be geared towards completing some end, which nevertheless never gets completed. Thus an agent may be building a house which never actually gets built, say because the funds for construction materials run out midway. We can perfectly felicitously say ' $A$ was building a house which was never built' - but only, of course, if we have recourse to the imperfective construction.

Equally significant later will be Mourelatos' observation in his seminal treatment of processes (1978), that actions are by no means the only kind of processes that exist. ${ }^{4}$ Photosynthesis, foetal development or a stone rolling downhill can all be seen as processual in nature, and will then be able to accommodate such time-related features as illustrated.

\footnotetext{
4 This is the main reason behind Mourelatos' urge to transform Vendler's (1957) and Kenny's (1963) familiar agentcentric taxonomy of 'activities', 'accomplishments', 'achievements' and (mental) 'states', to the 'topic-neutral' trichotomy of 'state', 'process', and 'event'.
} 
At least some of the above claims will no doubt be disputed by those who are unmoved by the plea to introduce processes into philosophy. ${ }^{5}$ Their rejoinders are not examined here (but see Gill, 1993 for one unsympathetic treatment of the process-view), since the aim of the present discussion, to repeat, is not to settle the debate between the process view and the rival camp. The central aim is rather to demonstrate the sort of work the process view, if accepted on the grounds adumbrated above, can do in solving a persistent puzzle such as ToK. Let us now turn to seeing this explicitly laid out.

\section{Solving the time of a killing problem}

It will be convenient to start with a process that is normally more protracted than killing, such as baking a cake. Suppose, then, that $A$ was baking a cake yesterday afternoon. He first whisked the flour with the baking powder, then mixed in the eggs and the sugar, then put the mixture in the oven. The cake then spent an additional forty minutes in the oven, at which point it was done. Let us now bring the lessons drawn in the previous section to bear on $A$ 's baking of the cake. Start with the imperfective paradox, which demonstrates the independence of an ongoing action from its successful completion. This implies that $A$ could have been baking a cake which never baked. And a fortiori, $A$ could have been baking the cake - indeed, he must have been doing so - for some time before the cake ultimately baked. There is nothing wrong with thinking (or saying) ' $A$ was baking a cake for two hours before it was finally baked'.

Next, recall Mourealtos' point that the domain of processes encompasses much more than just actions. And note that in the scenario as described, $A$ 's involvement in the cake's baking is over and done with by the time he places the cake in the oven. Putting these two observations together reveals that 'the baking of the cake' here refers to a process that is not purely or wholly agential

\footnotetext{
5 They may, for example, point out that we often speak as though events do exhibit the sort of temporal features the text denies they can accommodate. Thus we may say that The Hundred Year War grew increasingly more violent, or speak of an intermittent football practice. On the view endorsed here, these are roundabout ways of referring to the underlying process of which the events in question are composed. More on this below.
} 
throughout the entirety of its course. While in the initial phases or stages of the deed, $A$ is active, in the final stages - when the baking of the cake continues in the oven - he is no longer acting. ${ }^{6}$

It is here that the most crucial aspect of the process view comes into play, viz. how it enables a richer, and hence more faithful, representation of the particular temporal constituency of the occurrent in question. In the present case, this amounts to revealing the differences between distinct stages, or sub-processes, within the overarching process of the baking of the cake. That overarching process has an initial stage in which $A$ is acting, followed by another stage(s) in which $A$ is not acting. The initial stage is itself a process, comprised in turn of its own stages (whisking the flour, mixing in the eggs, etc.). Crucially, when the initial stage is completed, the process goes on: the cake continues to bake until it is done. What we have here, then, when fully articulated by the processual perspective, is an action-qua-process nested as a stage within a broader process of the baking of the cake. The same point can be put in terms of how the process changes in moving from one stage to the next.

We are now in a position to see how both parties to the debate over ToK go astray in viewing the occurrents in question as events. In so doing, both sides deprive themselves of the resources required to tease apart the point at which the queen's action is completed ( $\left.\mathrm{t}_{0}\right)$ from the point at which the killing of the king is completed $\left(t_{3}\right)$. In asking when the queen killed the king, they are led to compress the process and distort its temporality, creating a false dilemma which impales both views: that of pinpointing some single moment at which both the queen's action and the killing of the king simultaneously terminate. The Davidsonian, with her commitment to identifying the queen's poisoning of the king with the queen's action (i.e. her killing the king) opts for $\mathrm{t}_{0}$ as the single endpoint. This inevitably lands her in trouble with having to concede that the queen killed the king before his killing was completed.

\footnotetext{
${ }^{6}$ 'That $A$ 's involvement in the cake's baking was over some time before the cake was finally baked seems to rule out the so-called 'broad' use of the progressive, which would allow to describe $A$ as baking the cake even when he is temporarily doing something else while the cake is in the oven. More on broadness below.
} 
The Thomsonian meanwhile avoids this highly counterintuitive commitment by opting instead for $t_{3}$ as the endpoint. This allows her to affirm that the killing of the king is completed exactly when the king dies. But at the same time, it lands the Thomsonian in trouble in having to concede that the queen's action went on after the queen's involvement was over - at which point she may as well be dead as far as the process of the killing of the king is concerned.

When we view matters from the processual perspective, we avoid both pitfalls. We can say that the queen's action consists in her setting in motion and directing a process that resulted in the king's death, thereby satisfying the definition of 'to kill' as meaning 'to perform some action that is the primary cause of a death' (Silver, 2018: 1388), or alternatively perhaps 'To cause someone or something to die', as the Cambridge Dictionary has it. ${ }^{7}$ (It does not matter here which of the two is the correct definition, since the queen's action satisfies both.) But crucially, we need not, unlike the Davidsonian, concede that the queen killed the king before he died. What we say instead is that the queen was killing the king before the king died. And this is no stranger than saying that $A$ was baking the cake before it was baked. ${ }^{8}$ At the same time, we are not forced, unlike the Thomsonian, to accept the absurd claim that the queen killed (or was killing, for that matter) the king when the queen herself was already dead. For when the queen's engagement with the process of the king's killing is over, we can see the process as moving out of its agential phase and into its non-agential phase (which consists of its own subprocesses in the king's body, such as internal haemorrhaging, organ failure, etc.) - all the while remaining one and the same process that culminates in the king's death at $\mathrm{t}_{3}$.

In a sense, the proposal can be thought of as a compromise position, insofar as it rejects both the Davidsonian and the Thomsonian solutions while at the same time vindicating a key insight

\footnotetext{
7 See <https://dictionary.cambridge.org/dictionary/english/kill>.

8 Any lingering hesitation to accept ' $A$ was killing $B$ before $B$ died' as felicitous is, I submit, a pragmatic upshot of the fact that killings, unlike bakings, are typically not protracted occurrences, as they are in the case we are concerned with. This may make the imperfective use sound out of place here even though the circumstances make it perfectly apposite.
} 
driving each view, respectively. With the Thomsonian, we affirm that the killing of the king starts at $t_{0}$ and terminates at $t_{3}$. But since we see the killing of the king as a protracted process, which is equivalent to the queen's action for only part of the interval $t_{0}-t_{3}$, we crucially deny the Thomsonian claim that the queen's action lasted from $t_{0}$ to $t_{3}$. Similarly, while we affirm with the Davidosnian that the queen is no longer acting when she is done poisoning the king, we crucially deny the concomitant Davidsonian view of act-individuation, on which her solution to ToK is based, which sees the queen's movements in poisoning the king as equivalent to the killing of the king. ${ }^{9}$ For on the present line of thought, once again, 'the killing of the king' refers to a process that starts out being equivalent to the queen's action but later is not. ${ }^{10}$

Could, however, the main thrust of the proposed solution be captured using only the category of event (as an anonymous referee helpfully asked)? If it could, the plea to recognize processes for the prospect of an attractive solution to ToK will of course lose its force.

The attempt to demonstrate this possibility would likely involve something like the following paraphrase. Where the process-theorist claims, as above, that

When the queen's part in the process of the king's killing is over, we see the process as moving out of its agential phase and into its non-agential phase, all the while remaining one and the same process that culminates in the king's death,

\footnotetext{
9 The Davidsonian (sometimes also referred to as 'sparse') theory of act-individuation, mentioned earlier, is a central component of the overall Davidsonian theory of action. Hence, rejecting it constitutes a sharp departure from the Davidsonian solution, which otherwise may seem more aligned with the solution defended in the text, compared to the Thomsonian. Thanks to an anonymous referee for urging me to clarify.

10 One may wonder why we should accept, as the process-view's solution does, the Davidsonian suggestion that the queen's action terminates when she is no longer making any movements to administer the poison. (I thank an anonymous referee for pressing me on this point.) The problem of the acting dead was cited above as a reason for siding with the Davidsonian over the Thomsonian on this score. But the possibility of acting corpses is just one problematic symptom of a broader underlying mismatch between the Thomsonian proposal and the intuitive appearance. To see this, consider some common markers of action, such as the agent's ability to control what is taking place, and how it is taking place (more quickly, less painfully, etc. etc.); the exertion of effort on the agent's part; and the applicability of the reason-giving sense of 'why' one is acting. None of these markers apply to the part of the king's killing that starts when the poisoning is over: the queen has no control over that part of the process, its unfolding involves no effort on her part, and the special 'why?' question seems out of place there. The markers are telltale signs that an action is taking place; conversely, their absence should convince us that no action is.
} 
the event-theorist might instead claim that

When the queen's part in the event of the king's killing is over, we can see the event's agential phase get succeeded by its non-agential phase, all the while remaining one and the same event that culminates in the king's death.

But the paraphrase falls short. It fails to explicitly represent a crucial component of the eventtheorist's view, viz. that actions are events. When this component is brought into the picture, 'the event's agential phase' must be seen as itself referring to an event - the event of the queen's killing the king. And at that point, a problem very much like the one originally afflicting the Davidsonian line resurfaces. For it turns out that the event which is the queen's killing of the king is completed sometime before the king dies - in other words, it turns out that the queen killed the king before he died.

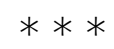

It may seem odd if the upshot of the argument of this paper were some sort of general error theory about such an elementary practice as asking and answering questions about when $A V$-ed. But that is not quite the upshot. While trading in events, as we do when we ask when $A V$-ed, does generally conceal the temporal constituency of $A$ 's $V$-ing as demonstrated above, in normal circumstances the active process and the event overlap entirely or almost entirely so there need be no salient mismatch with respect to their spatiotemporal locations. This is true of numerous acttypes (think of swimming forty laps, reading Hamlet, scratching an itch, etc. etc.) It is similarly true in the range of cases where the so called 'broad' use of the imperfective is applicable - that is, when actions are ascribed to agents even though they are temporarily not directly engaged in the process. Thus consider 'She is baking a cake', said of someone lying on the couch while waiting for the mixture to set before covering it with chocolate cream. Here too, the event-ideology's abstraction from the temporal constituency of the process does not stand in the way of seeing both event and process as collocated. In this way, much of our everyday practice, which may seem 
committed to actions being events, can still be rehabilitated as a roundabout way of referring to the underlying processes. After all, the event of $A$-s $V$-ing is no more and no less than a snapshot of the completed process of $A$ 's $V$-ing. It is only when the active (agential) process is pulled apart from the event's terminus that puzzles seem to arise if our ontology is not careful enough. For in such cases, one's action consists of engaging in one part of the process which, by the time it is over and we have the completed event, one is no longer engaged in.

\section{ACKNOWLEDGEMENTS}

In writing this paper, I benefited greatly from discussions with David Kovacs, David Jenkins, and David Hillel Ruben. Many thanks also to John Hyman, Benzion Ovadia, Ruth Weintraub, and an anonymous referee for their detailed and very helpful written comments on previous drafts.

\section{REFERENCES}

Anscombe, G. E. M. (1957). Intention. Oxford: Basil Blackwell.

Bach, K. (1980). Actions are not events, Mind, 89, 114-20.

Bennett, J. (1988). Events and Their Names. Oxford: Oxford University Press.

Davidson, D. (1980). Essays on Actions and Events. Oxford: Oxford University Press.

Galton, A. and Mizoguchi, R. (2009). The water falls but the waterfall does not fall: new perspectives on objects, processes and events. Applied Ontology, 4, 71-107.

Gill, K. (1993). On the metaphysical distinction between processes and events. Canadian Journal of Philosophy, 23, 365-84.

Hornsby, J. (2012). Actions and activity. Philosophical Issues, 22, 233-245.

Kenny, A. (1963). Action, Emotion and Will. London: Routledge and Kegan Paul.

Lombard, L. B. (1986). Events: A Metaphysical Study. London: Routledge and Kegan Paul.

Mourelatos, A. (1978). Events, processes and states. Linguistics and Philosophy, 2, 415-434.

Neale, S. (1993). Descriptions. Cambridge, MA: MIT Press.

Ruben, D. (1999). Act individuation: the Cambridge theory. Analysis, 59(4), 276-283.

Silver, K. (2018). The vague time of a killing. Philosophical Studies, 175, 1383-1400.

Simons, P. (1987). Parts: A Study in Ontology. Oxford: Oxford University Press.

Steward, H. (2013). Processes, continuants, and individuals. Mind, 122, 781-812. 
Steward, H. (2012). Actions as processes. Philosophical Perspectives, 26, 373-388.

Stout, R. (ed.) (2018). Process, Action, and Experience. Oxford: Oxford University Press.

Thomson, J. J. (1971). The time of a killing. The Journal of Philosophy, 68, 115-132.

Vendler, Z. (1957). Verbs and times. Philosophical Review, 66, 143-160. 